\title{
Recycled Aggregates Concrete Compressive Strength Prediction Using Artificial Neural Networks (ANNs)
}

\author{
Mohamad Ali Ridho B K A ${ }^{1,2} \mathbb{D}$, Chayut Ngamkhanong ${ }^{1,2} \mathbb{D}$, Yubin $\mathrm{Wu}^{2}(\mathbb{D})$ and Sakdirat Kaewunruen ${ }^{1,2, *(\mathbb{D})}$ \\ 1 Birmingham Centre for Railway Research and Education, School of Engineering, University of Birmingham, \\ Birmingham B15 2TT, UK; MXK152@student.bham.ac.uk (M.A.R.B.K.A.); cxn649@bham.ac.uk (C.N.) \\ 2 Department of Civil Engineering, School of Engineering, University of Birmingham, Birmingham B15 2TT, \\ UK; YXW1077@student.bham.ac.uk \\ * Correspondence: s.kaewunruen@bham.ac.uk
}

Citation: B K A, M.A.R.; Ngamkhanong, C.; Wu, Y.; Kaewunruen, S. Recycled Aggregates Concrete Compressive Strength Prediction Using Artificial Neural Networks (ANNs). Infrastructures 2021, 6, 17. https://doi.org/ 10.3390/infrastructures6020017

Academic Editor: Kevin Paine Received: 25 December 2020

Accepted: 20 January 2021

Published: 23 January 2021

Publisher's Note: MDPI stays neutral with regard to jurisdictional claims in published maps and institutional affiliations.

Copyright: (c) 2021 by the authors. Licensee MDPI, Basel, Switzerland. This article is an open access article distributed under the terms and conditions of the Creative Commons Attribution (CC BY) license (https:// creativecommons.org/licenses/by/ $4.0 /)$.
Abstract: The recycled aggregate is an alternative with great potential to replace the conventional concrete alongside with other benefits such as minimising the usage of natural resources in exploitation to produce new conventional concrete. Eventually, this will lead to reducing the construction waste, carbon footprints and energy consumption. This paper aims to study the recycled aggregate concrete compressive strength using Artificial Neural Network (ANN) which has been proven to be a powerful tool for use in predicting the mechanical properties of concrete. Three different ANN models where 1 hidden layer with 50 number of neurons, 2 hidden layers with (50 10) number of neurons and 2 hidden layers (modified activation function) with (60 3) number of neurons are constructed with the aid of Levenberg-Marquardt (LM) algorithm, trained and tested using 1030 datasets collected from related literature. The 8 input parameters such as cement, blast furnace slag, fly ash, water, superplasticizer, coarse aggregate, fine aggregate, and age are used in training the ANN models. The number of hidden layers, number of neurons and type of algorithm affect the prediction accuracy. The predicted recycled aggregates compressive strength shows the compositions of the admixtures such as binders, water-cement ratio and blast furnace-fly ash ratio greatly affect the recycled aggregates mechanical properties. The results show that the compressive strength prediction of the recycled aggregate concrete is predictable with a very high accuracy using the proposed ANN-based model. The proposed ANN-based model can be used further for optimising the proportion of waste material and other ingredients for different targets of concrete compressive strength.

Keywords: recycled aggregates; compressive concrete strength; machine learning; artificial neural network; prediction model; concrete engineering

\section{Introduction}

With the widespread popularisation and application of new modern technologies, the development of industrialisation worldwide is accelerating, and resources consumption and environmental damages are becoming extremely worrying. As a result, more construction waste has been accumulated from time to time. Generally, the compositions of construction waste are: concrete, muck, masonry, wood, metal, mortar, asphalt, decorative materials and other wastes [1]. Throughout the development process of human civilisation construction, concrete materials began to be produced and used as early as the early 19th century [2]. At present, it is one of the most widely used as the building materials in the construction industry [3-5]. With the rapid economic development and the acceleration of urbanisation, the per capita consumption of concrete materials is increasing day by day. Concrete is mainly composed of coarse aggregate (stone) and fine aggregate (sand) [6]. These two aggregates account for about $75 \%$ of the total concrete. In the past economic construction process, resource protection and environmental protection awareness did not receive enough attention, thinking that sand and gravel aggregates have wide sources, low 
prices, inexhaustible resources, and extensive exploitation, and even abuses phenomenon, causing serious damage to the natural ecological environment [7-11]. As the pillar industry of the national economy, the construction industry has increased the demand for aggregate sand and gravel as the world population continues to increase.

At the same time, the long-term exploitation and consumption of resources will inevitably lead to resource depletion [12]. The original rich sand and gravel resources no longer exist, and the shortage of aggregates and environmental pollution are replaced. The natural formation of natural sand and gravel requires a long geological age or even longer. It is a non-renewable resource. In future, due to large-scale exploitation without relevant protection measures, natural aggregates will inevitably face shortages. On the other hand, with the arrival of the useful life of the cement structure, a large number of buildings will be demolished, and a large amount of waste concrete will inevitably be produced [8,13-15]. A large amount of construction waste is generated every year around the world.

Besides, in recent years, natural disasters have occurred frequently in various countries around the world, and the resulting construction waste also needs to face practical problems such as how to be properly recycled, processed and reused [14,16]. Recycled concrete technology is one of the main measures to realise the sustainable development of building resources and environment. The development and application of recycled concrete technology can solve the problems of large amounts of waste concrete treatment difficulties and the resulting deterioration of the ecological environment [17].

The preparation of recycled aggregate concrete is not essentially different from ordinary concrete. Only part of the cement and aggregate will be replaced. Due to the presence of the original mortar layer on the surface of the waste concrete in the crushing process, the quality of the recycled concrete is not as good as that of ordinary concrete, which will make a large amount of waste concrete not well used $[18,19]$. The source of most aggregates in concrete is produced under natural conditions, that is, blast mining in quarries or excavation in riverbeds. The advantage is that the quality is guaranteed, but the disadvantage is that these raw materials cannot be provided in unlimited quantities and their development and production have a huge impact on the local ecological environment.

Recycling concrete aggregates to replace natural aggregates is one of the important means for sustainable development and resource recycling. In addition, the use of waste concrete as a raw material can reduce a large amount of waste dumping. The recycled concrete aggregate is mainly composed of the original natural aggregate used to prepare the original concrete and the original mixture cement mortar adhered to the surface of the original natural aggregate [20]. The performance of concrete containing recycled aggregate depends to a large extent on the mortar content of the recycled aggregate, and the mortar content depends on the strength of the original concrete recovered from the recycled aggregate. The amount of mortar adhering to recycled aggregate depends on the crushing process and the water-cement ratio of the original concrete [21].

The proportion of mortar attached to the surface of the recycled aggregate can be reduced by crushing the recycled aggregate to a size close to that of the natural gravel aggregate in recycled concrete [22-24]. The basic characteristics of undisturbed concrete, the production process of recycled aggregates and the aggregate particle size fraction are the three most important factors that determine the performance of recycled concrete aggregates [25-27]. The changes in the proportion of admixtures, coarse aggregates, and fine aggregates affect the strength of concrete. The performance of concrete is an important reference index for designing concrete mix ratio [28]. In addition, the relationship between mix ratio and performance is not a simple linear relationship but an extremely complex nonlinear relationship. It is noted adding recycled aggregate leads to even more complex relationship and proportion in order to use the standard mix design for predicting the mechanical properties of the concrete. In recent years, many experiments and research methods have been developed in order to predict the strength of a certain mix ratio faster. Various methods of machine learning are also used to predict the strength of various types of concrete. As the name suggests, machine learning is a subject that studies how to use 
machines to simulate human learning activities [29]. A stricter formulation is: machine learning is the study of machines to acquire new knowledge and new skills and to recognise existing knowledge.

Unlike traditional model-driven methods, machine learning is data-driven. It explores and builds algorithms that learn from data and predict data. Most traditional statistical models have certain requirements or assumptions for the specific distribution of data. However, in reality, real data may not meet those assumptions or requirements. Some of their excellent properties are impossible to get, and even some conclusions are wrong. In this case, the machine learning method is more reasonable. The machine learning method does not need to make any assumptions about the data distribution, and the results produced can also be evaluated by cross-validation [30].

Recently, artificial intelligence has been implemented to study the recycled aggregates mechanical properties such as compressive strength and tensile strength. For instance, Naderpour et al. [31] developed an Artificial Neural Network (ANN) model from 139 datasets to predict the recycled aggregates compressive strength. They concluded that ANN method is capable of high accuracy predictions for recycled aggregates compressive strength. Furthermore, the 28 days compressive strength of recycled concrete was predicted Automated Neural Network Search (ANNS) considering water, cement, fine aggregate, coarse aggregate and recycled aggregate as input variables [32]. The R-squared value was very high showing that the prediction model could be trustable. However, the samples were limited to only 40. On the other hand, Deng et al. [33] proposed a convolutional neural network (CNN) model to predict the recycled aggregate compressive strength. The outcome of this research is CNN model able to predict the compressive strength with high accuracy, high efficiency and higher generalisation ability by learning the deep features of water-cement ratio and other admixtures combination. In another research, Tu et al. [34] implemented genetic algorithm-backpropagation (GA-BP) model to predict the recycled aggregate thermal insulation concrete. Based on the research outcomes, the GA-BP reduced the orthogonal experimental process based on the training sample data and GA-BP neural network has more stable and better generalisation performance than backpropagation neural network. Alabi et al. [35] developed ANN model to predict the compressive strength and split tensile strength of recycled aggregate concrete containing lathe waste steel fibre which the outcomes concluded that ANN approach provides a powerful tool to study the estimation of recycled aggregates compressive strength and split tensile strength. However, the sample sizes were very limited in the previous studies showing that the models may not adequately reliable for future use.

Nevertheless, the ANN model performance is greatly affected by its architecture. The parameters of the model are obtained by trial-and-error method. The process of finding the optimum architecture is time-consuming. Moreover, the compressive strength of the recycled aggregate depends on the recycled aggregates admixtures proportions. The variability in the characteristics of the recycled aggregates makes it more complicated to predict and understand the non-linear relationship between the compressive strength of recycled aggregates and its mixing ratio [33]. Thus, this study aims to create a more accurate and cost-effective prediction model of the compressive strength of concrete on the basis of different proportions of various components including recycled waste material. Several modifications such as number of hidden layers, number of neurons in hidden layer and modification of activation function are studied in order to obtain high efficiency and high prediction accuracy prediction model and also to understand the parameters that affect the performance of the ANN models. Firstly, this article is based on investigating the status of recycled concrete waste in various countries around the world and grasps the latest technology research trends. The 1030 raw data of different mixtures have been collected from the literature and previous experimental results. Note that blast furnace slag is considered as recycled aggregates mixed in concrete. This study considers 8 inputs parameters: water, cement, fine aggregate, coarse aggregate, blast furnace slug, fly ash, superplasticizer and day. Secondly, the collected relevant data of recycled aggregate 
concreted are then used to develop concrete compressive strength prediction models by using Artificial Neural Network (ANN) approach in order to study the impact of recycled aggregates on the strength of recycled concrete using Levenberg-Marquadt (LM) which can provide better speed and performance than others because of its flexibility to solve multidimensional problems Moreover, LM is remarked as the best algorithm to predict concrete behaviour [36,37]. Note that ANN offers quick learning with an accurate performance for capturing the intrinsically nonlinear nature of patterns in the concrete properties and reducing the cost, as well as saving time in the class of compressive strength's determination problems. Lastly, three different prediction ANN-based models of concrete compressive strength are constructed and compared in this study. The best model can be used to predict the recycled aggregate concrete compressive strength considering blast furnace slug and various general input parameters based on the user's resources and objectives.

\section{Methodology}

\subsection{Artificial Neural Network Model Training and Dataset}

\subsubsection{Artificial Neural Network}

An artificial neural network (ANN) is a data prediction framework based on existing features created from the human mind structure. This network is made of some functional blocks, which are named neurons. Neurons are connected by weights, which are usually randomly selected at first. Weights in a learning process are increased or decreased by some epochs to eventually achieve the desired network which can predict it by reasonable accuracy [30].

Therefore, in a trained neural network, the desired output can be achieved by receiving the inputs and considering the updated weights as shown in Figure 1. The network improves over time by comparing the desired input and output and calculating the error. The improvement of the machine learning model from time to time indicates the accuracy of the prediction model can be improved and the predicted results are reliable.

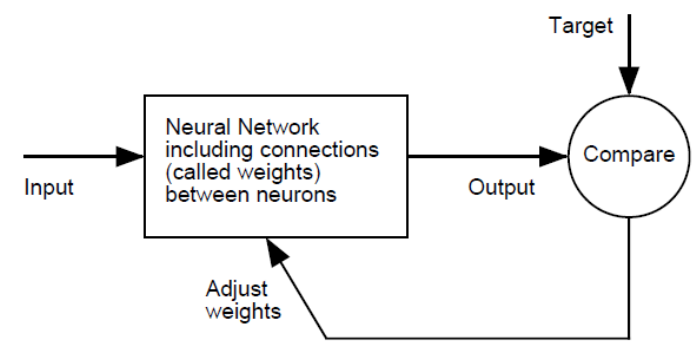

Figure 1. Artificial neuron model.

Usually, nonlinear activation functions like sigmoid (tansig and logsig) are used because of a better response. The training purpose of an artificial neural network is to minimise the error function that is usually mean square value (MSE).

$$
\operatorname{MSE}(\text { mean square value })=\frac{1}{N} \sum_{i=1}^{n}\left(t_{i}-a_{i}\right)
$$

where $\mathrm{N}$ is the number of input parameters, the output is shown by $t_{i}$, parameter $a_{i}$ are desired outputs (targets).

Xlsread function is used to import the datasets in Xls format into MATLAB as shown in Figure 2. Then, Neural Net Fitting app in MATLAB is used to sort the data and select input and output parameters. Then, the modifications of number of hidden layers are done using nftool in MATLAB by coding an advance script as explained in Section 2.2.2. Backpropagation algorithm Levenberg-Marquardt is chosen as a training algorithm for better curve fitting (regression) and performance. 


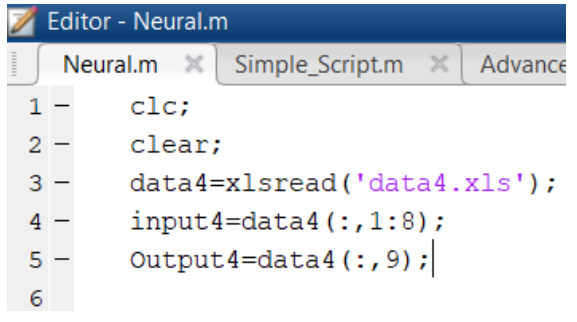

Figure 2. Xlsread function.

\subsubsection{Dataset}

The collected datasets are used for predicting concrete compressive strength consists of 8 parameters which are cement, blast furnace slag, fly ash, water, superplasticizer, coarse aggregate, fine aggregate, and age(day), as shown in Table 1 . Table 2 shows the target output of concrete compressive strength $(\mathrm{MPa})$, which will be predicted by ANN in this study.

Table 1. Parameters of recycled concrete.

\begin{tabular}{cccc}
\hline Parameter & Unit & Min & Max \\
\hline Cement & $\mathrm{kg} / \mathrm{m}^{3}$ & 102 & 540 \\
Blast Furnace Slag & $\mathrm{kg} / \mathrm{m}^{3}$ & 0 & 359.4 \\
Fly Ash & $\mathrm{kg} / \mathrm{m}^{3}$ & 0 & 200.1 \\
Water & $\mathrm{kg} / \mathrm{m}^{3}$ & 121.8 & 247 \\
Superplasticizer & $\mathrm{kg} / \mathrm{m}^{3}$ & 0 & 32.2 \\
Coarse Aggregate & $\mathrm{kg} / \mathrm{m}^{3}$ & 801 & 1145 \\
Fine Aggregate & $\mathrm{kg} / \mathrm{m}^{3}$ & 594 & 992.6 \\
Age & Day & 1 & 365 \\
\hline
\end{tabular}

Table 2. Prediction of concrete compressive strength by artificial neural network (ANN).

\begin{tabular}{cccc}
\hline Parameter & Unit & Min & Max \\
\hline Concrete compressive strength & MPa & 2.3318 & 82.59 \\
\hline
\end{tabular}

The data and range of each parameter are then normalised (except Age) in Table 3 to make them more suitable for performing the activation function on them so that, in addition to performing more accurate and easier calculations, the speed of network training is also increased. Without the data normalisation process, the training process may not lead to the desired result, and also the data processing may be heavy and slow and may not be accurate enough. Normalising data can also reduce data duplication and similarity between them so that there are purer and smaller datasets.

Table 3. Normalised data used for training artificial neural networks.

\begin{tabular}{ccc}
\hline Parameter & Min & Max \\
\hline Cement & 0.0448 & 0.2254 \\
Blast Furnace Slag & 0 & $0.150 \mathrm{~g}$ \\
Fly Ash & 0 & 0.0888 \\
Water & 0.0514 & 0.1122 \\
Superplasticizer & 0 & 0.0131 \\
Coarse Aggregate & 0.3459 & 0.4798 \\
Fine Aggregate & 0.2480 & 0.4141 \\
Age & 1 & 365 \\
\hline
\end{tabular}




\subsection{MATLAB Neural Fitting}

Firstly, the raw data, which consists of input and output data, must be imported into the workspace. It can be done by the Xlsread function which can import Xls format data to the MATLAB. Neural Net Fitting, which is chosen as the training application, can be started in MATLAB as illustrated in Figure 3. Then, input and output should be selected as shown in Figure 4. There are 1030 data sorted in matrix rows in total. It can be seen that 1030 datasets of variables contain 8 inputs (parameters presented in Table 3) and 1 output (concrete strength).

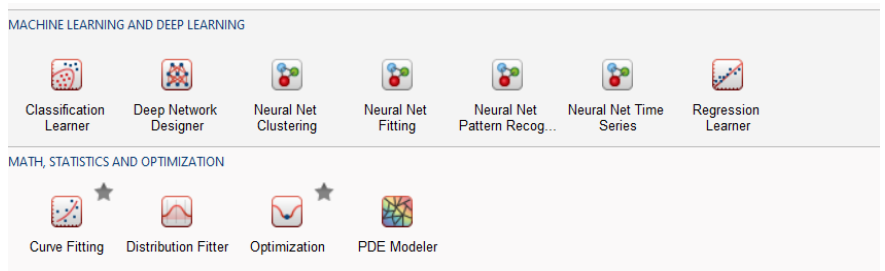

Figure 3. Neural Net Fitting.

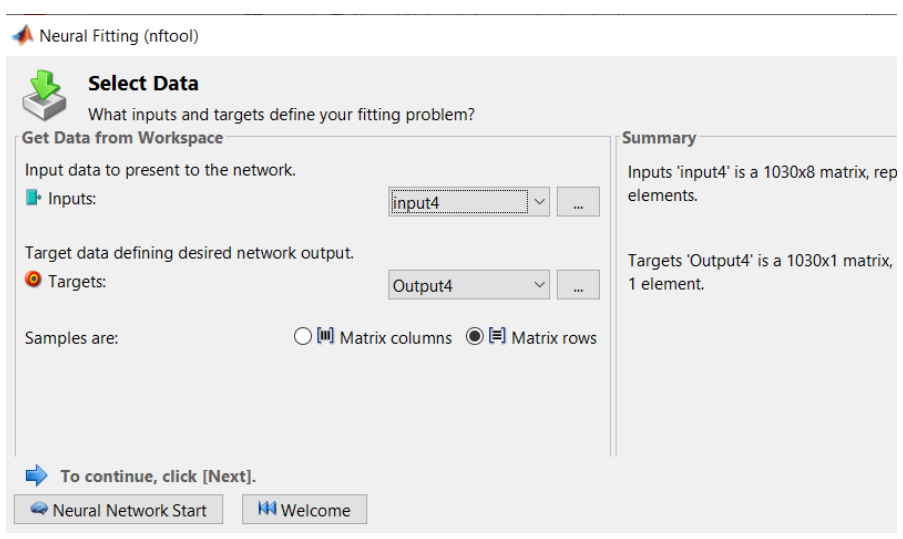

Figure 4. Selecting input and output (Target) matrix.

All the input data are randomly divided into three aspects: training, validation and testing. The next step is to define the fixed allocation ratio for training, validation and testing as $70 \%, 15 \%$ and $15 \%$, respectively, as shown in Figure 5 .

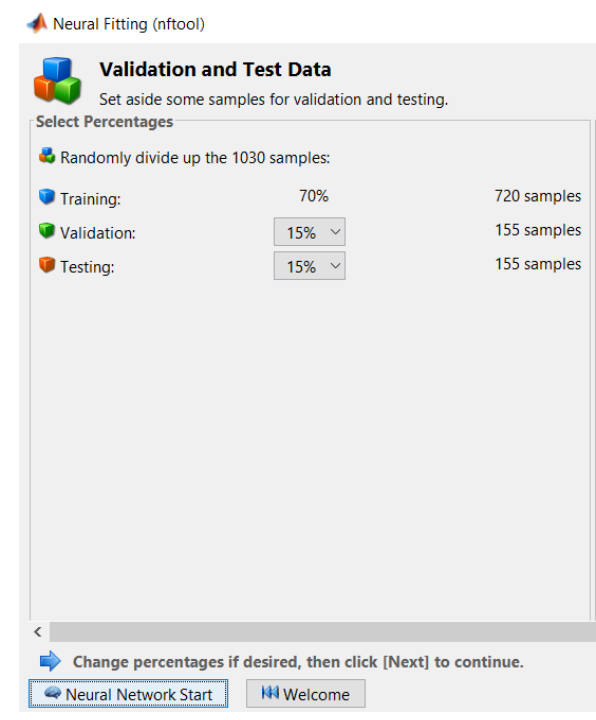

Figure 5. Dividing up samples. 


\subsubsection{Layers (1 Hidden Layer with 50 Neurons)}

The number of hidden neurons must be set in the hidden layer which going to be used for our purpose. Fifty neurons were selected. Neural fitting tools select 1 hidden layer by default but it can be changed in the future by editing Advanced-Script which nftool will make at the end of the training.

There are different algorithms in the MATLAB toolbox for updating weights. Some of them are Levenberg-Marquardt, Bayesian regularization, and scaled conjugate gradient. Levenberg-Marquardt backpropagation algorithm is one of the most popular algorithms in the MATLAB toolbox. It is one of the fast algorithms which has reasonable performance and is used more than the other ones. This algorithm has better regression (curve fitting). So, Levenberg-Marquart (trainlm) is chosen as a training algorithm. The First step is to import input data and find outputs using initial random weights. It is clear that because of random weights the error will be high in this step and outputs are far from the target. The second step is to calculate errors in hidden layers neurons. Then, the weights will be updated. In the next step, outputs will be calculated and backpropagation will be done from the output. This way helps neurons to update the weights.

Each layer has an activation function. After that, weights will be updated and one epoch will be done. Figure 6 shows the structure of the neural network. Usually, this process will repeat for several epochs. This can help the network to find its better performance. Now the network is ready to train. Table 4 show the features below.

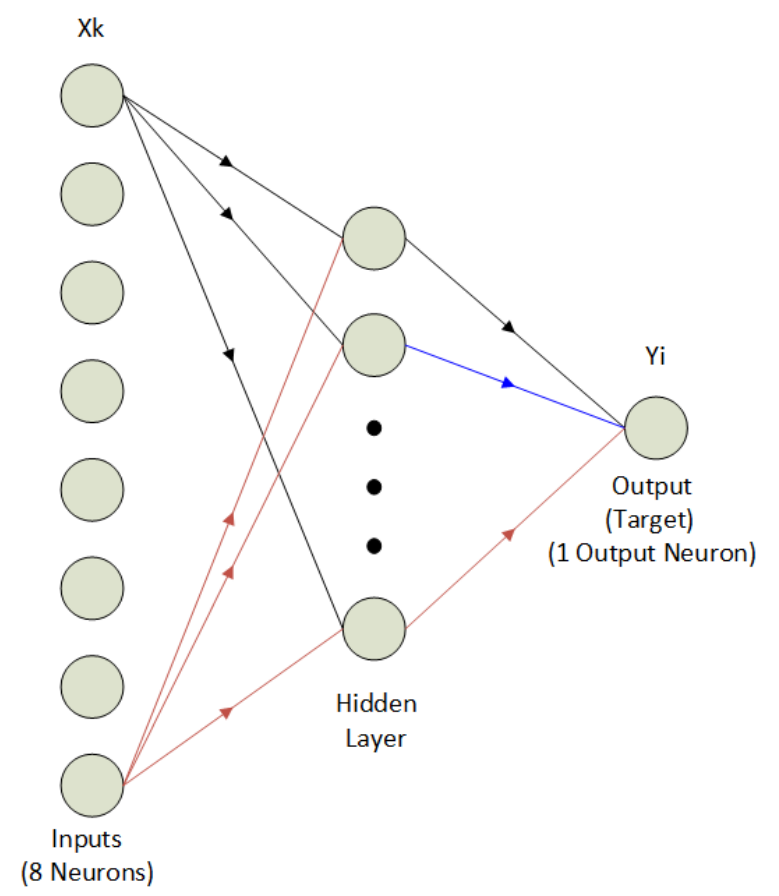

Figure 6. Structure of neural network.

Table 4. Features of neural network.

\begin{tabular}{cc} 
Inputs & 8 \\
Number of hidden layers & 1 \\
Neurons of hidden layer & 50 \\
Training algorithm & Levenberg-Marquadt \\
The activation function of the hidden layer & Sigmoid \\
\hline
\end{tabular}




\subsubsection{Hidden Layers}

Some features and parameters of the ANN must be changed for finding better accuracy. One option is to increase the number of hidden layers. Usually, the best option is to have 2 hidden layers. In this study, the Advanced-Script shown in Figure 7 helps to achieve this.

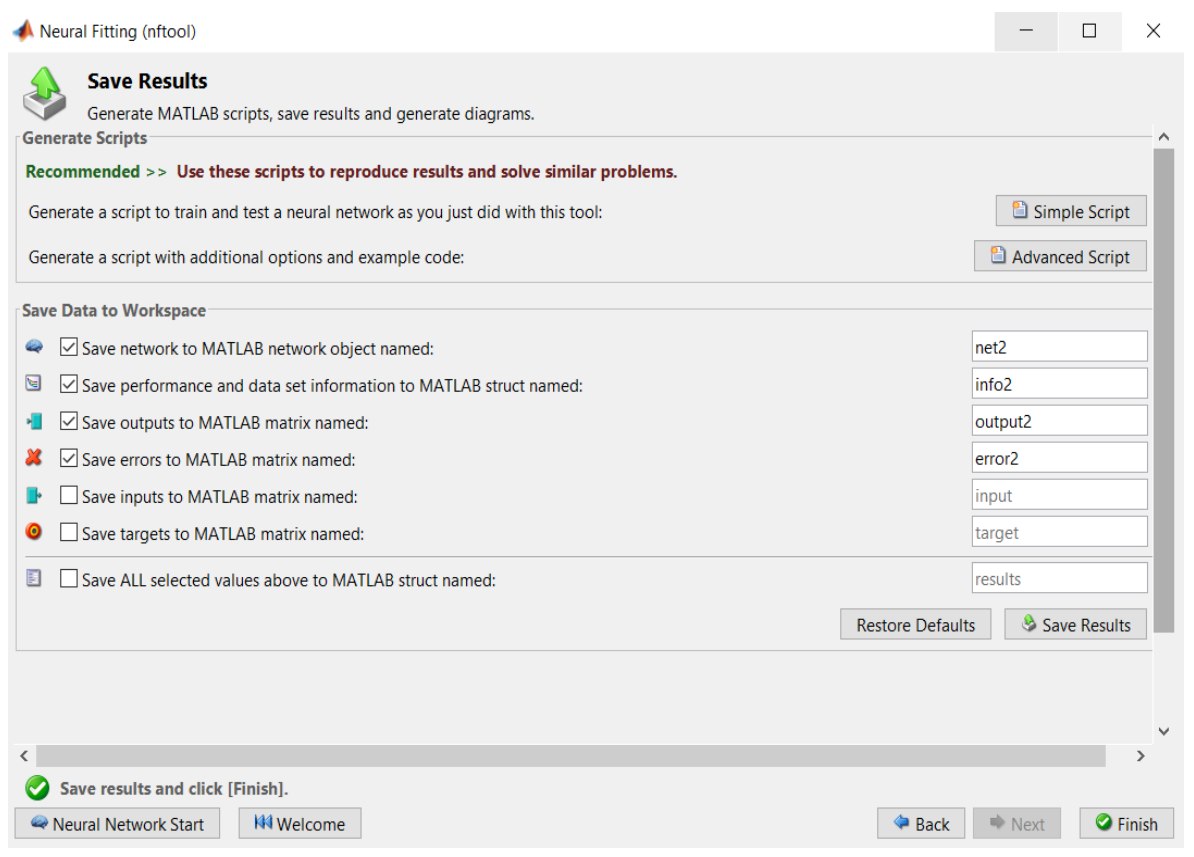

Figure 7. Advance Script.

The network parameters undergo some modifications. At line 26, another hidden layer is added, as shown in Figure 8, with 10 neurons to see whether the error will be reduced or not.

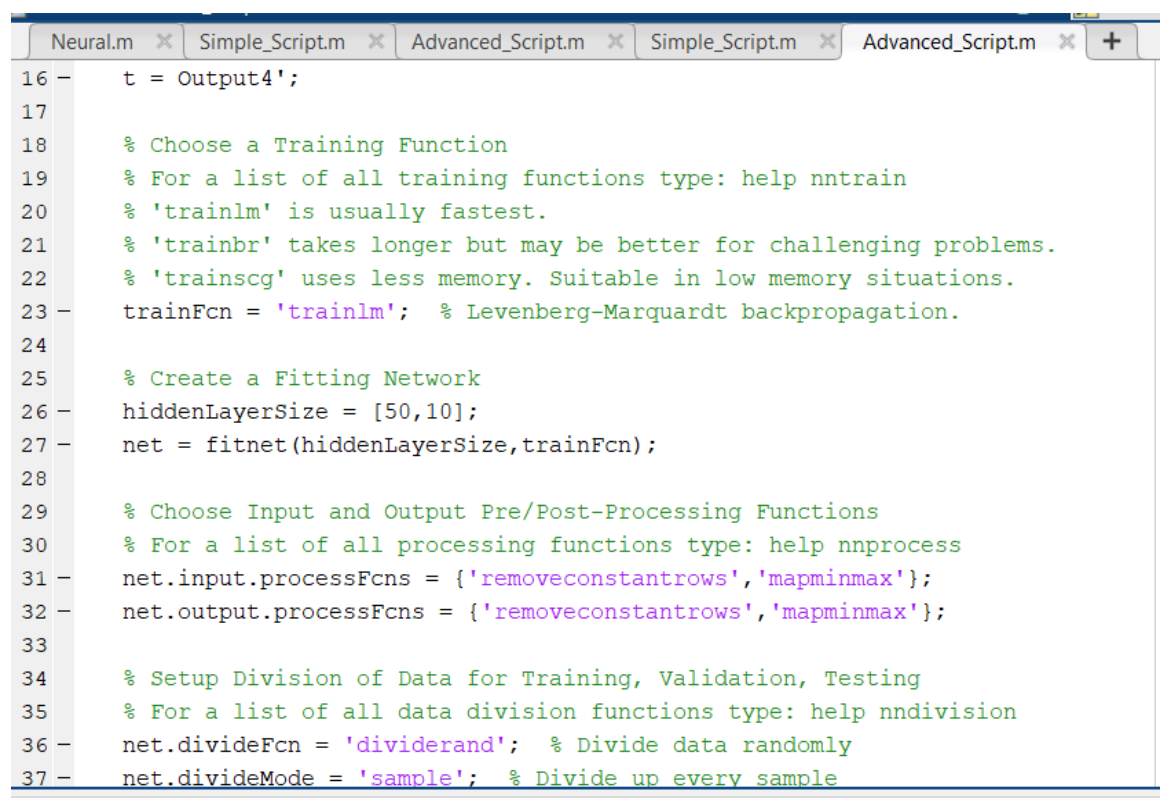

Figure 8. Addition of hidden layer.

\subsubsection{Hidden Layers with Customising Activation Function}

For the modifications of activation functions, the newff function was used to allow the customization of the network. The (603) neurons have been used for 2 hidden layers. 
Logsig and tansig are also used as transfer (activation) functions of hidden layers. The output layer has a purelin activation function like before as shown in Figure 9.

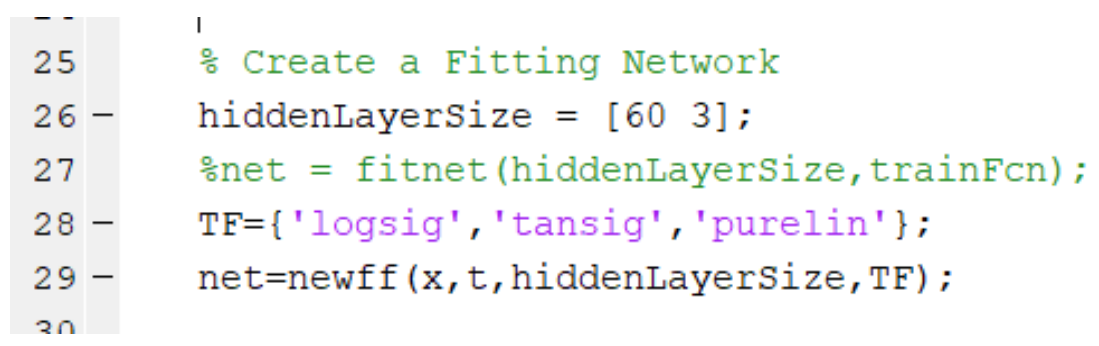

Figure 9. Different activation functions.

After running the new code, a neural network structure that has new activation functions for the first hidden layer will be created as shown in Figure 10. Table 5 shows the new artificial neural network features.

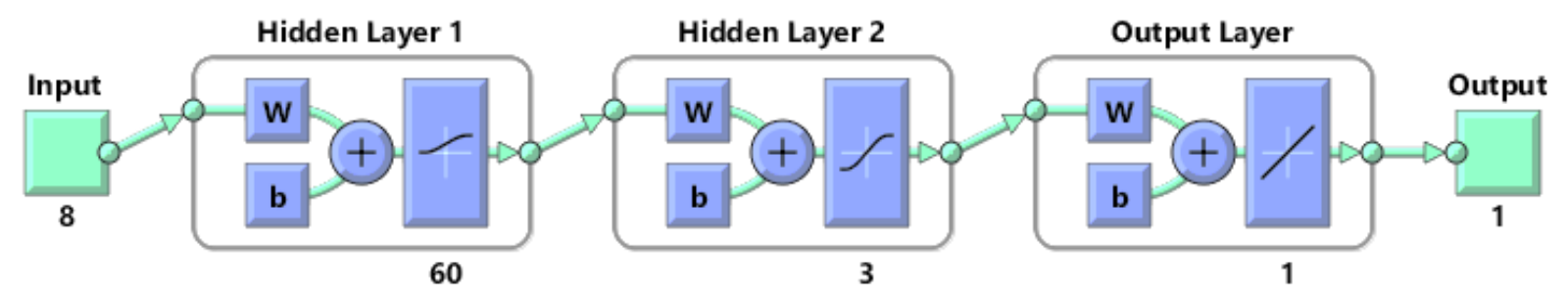

Figure 10. New neural network structure with activation function.

Table 5. New artificial neural network features.

\begin{tabular}{cc} 
Inputs & 8 \\
Number of hidden layers & 2 \\
Neurons of hidden layer & $(603)$ \\
Training algorithm & Levenberg-Marquadt \\
The activation function of the first hidden layer & Logsig \\
The activation function of the second hidden layer & Tansig \\
\hline
\end{tabular}

\section{Results and Discussions}

\subsection{Hidden Layer with 50 Number of Neurons}

The performance plotted in Figure 11 shows iterations that the process of training has been done. It specifies how much is the final error and gradient. A model of ANN with nodes and one hidden layer has been defined and error decreased up to 34.81. The training process ended at the 19th iteration where it is not the best choice for a trained network. The algorithm chooses the 13th iteration because it has a less valid error in comparison to the training error. It means, by continuing the process, the iteration may have better performance for training data but it can make test data or valid data performance worse. The minimum mean squared error (MSE) is 34.81 at iteration 13. 


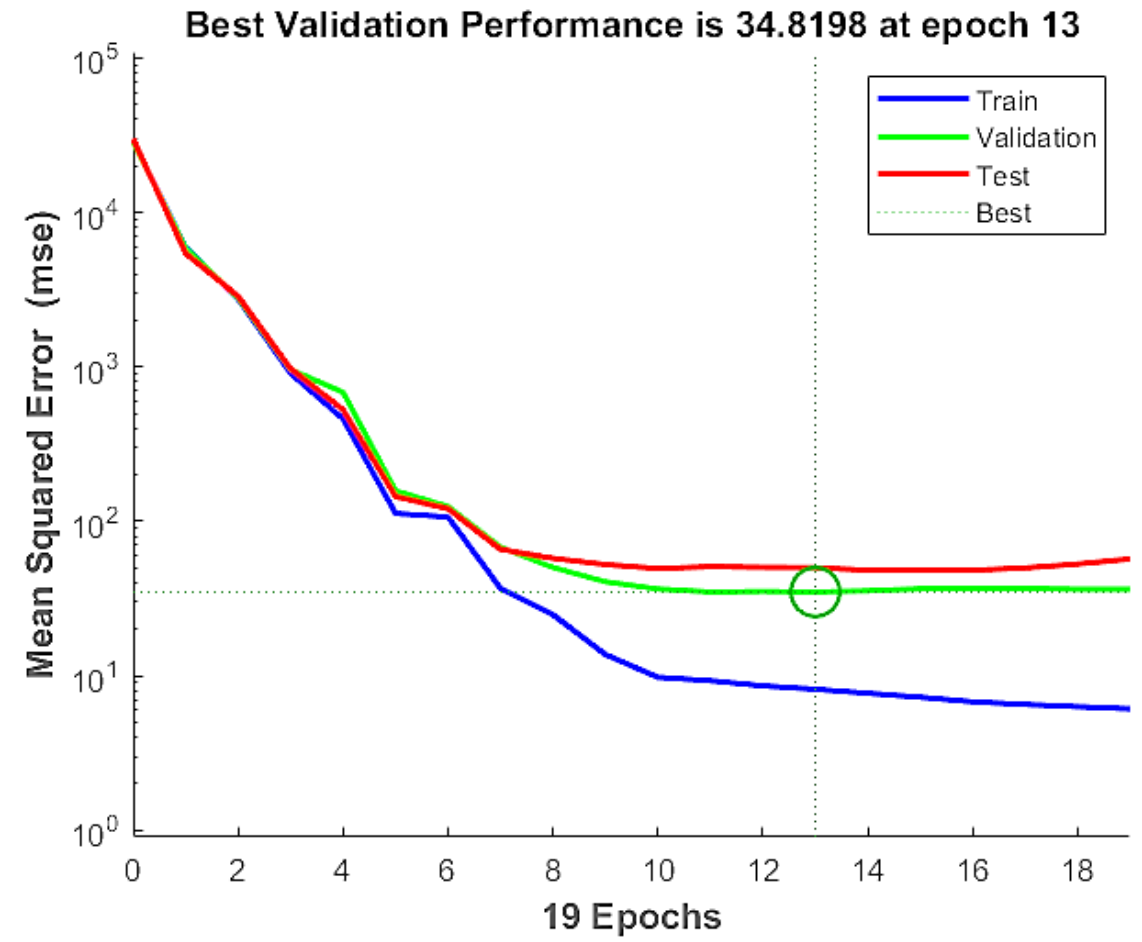

Figure 11. New neural network structure with activation function.

Although training data errors will decrease in later periods, validation and test data's error increase, that is why iteration 13 is the best choice for this neural network training. $\mathrm{Mu}$ is the learning rate in the Levenberg-Marquardt algorithm and after some iteration, 0.01 was selected in Figure 12. It is clear that after 6 validation fails, the process of training has been stopped.

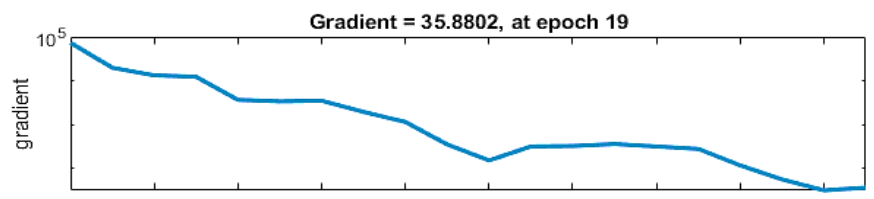

(a)

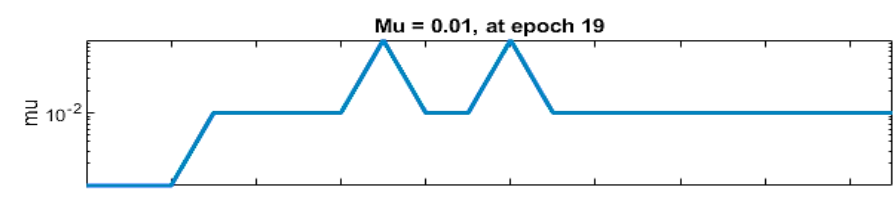

(b)

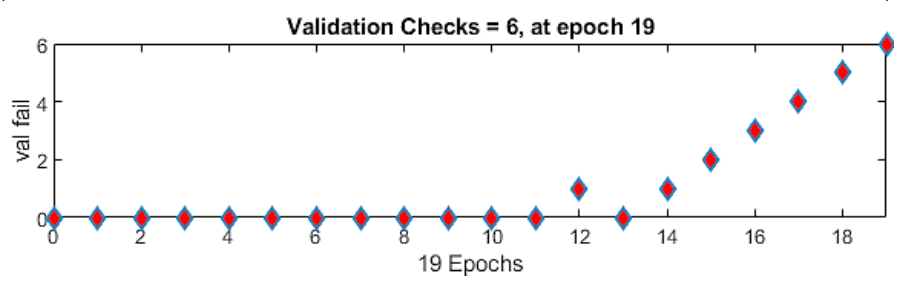

(c)

Figure 12. Neural network training state. (a) Gradient graph at epoch 19; (b) Mu graph at epoch 19; (c) Validation checks at epoch 19.

Regression for training data, validation data, and Test data is shown in Figure 13. The line fits the test data with a slope of 0.924 and it is reasonable. 


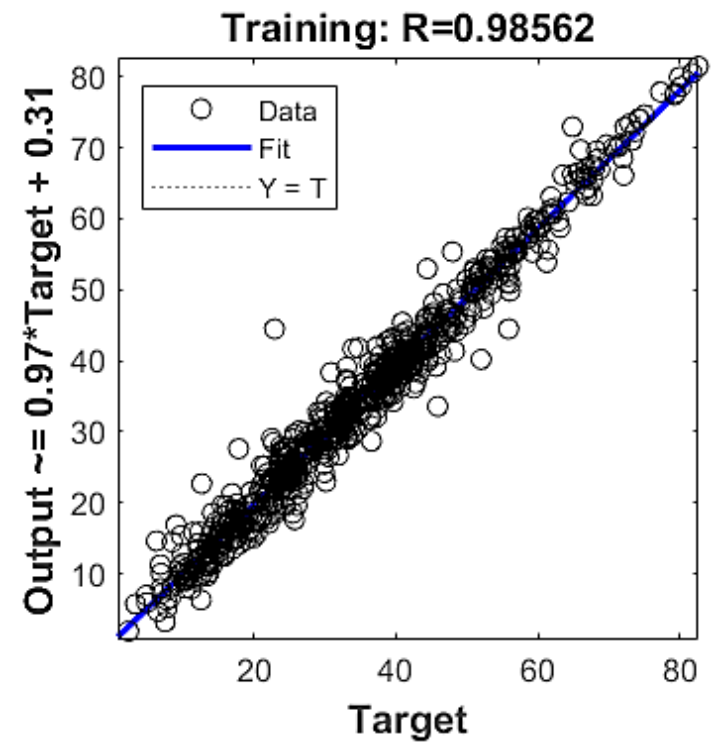

(a)

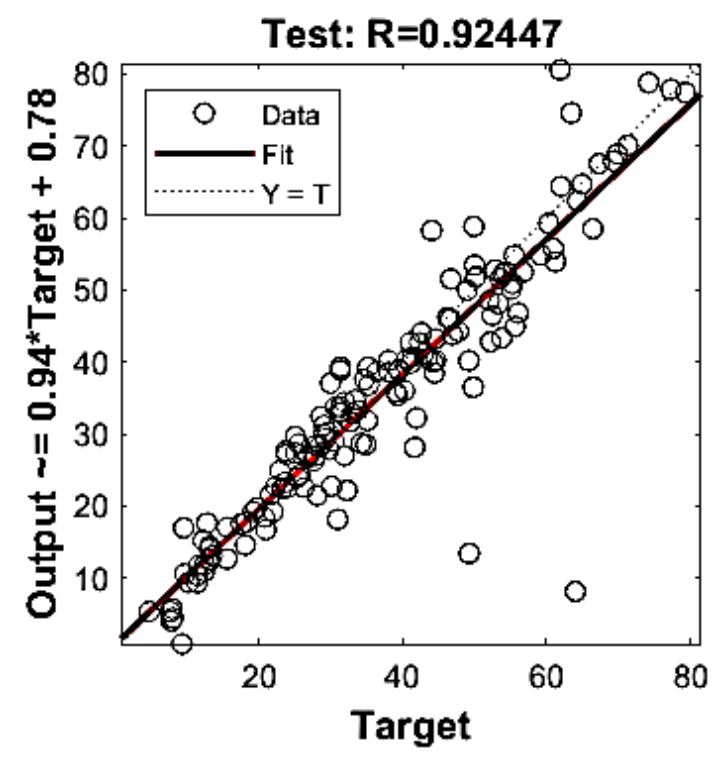

(c)

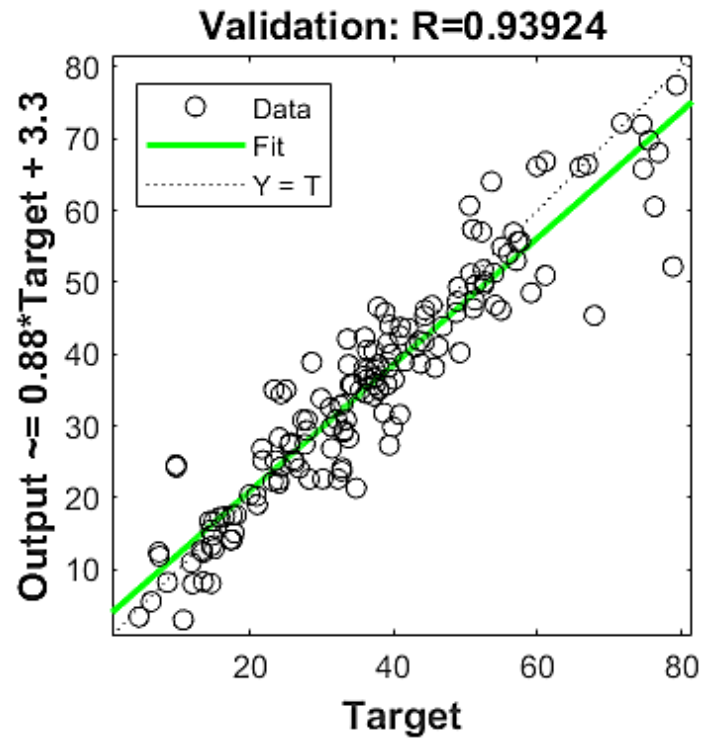

(b)

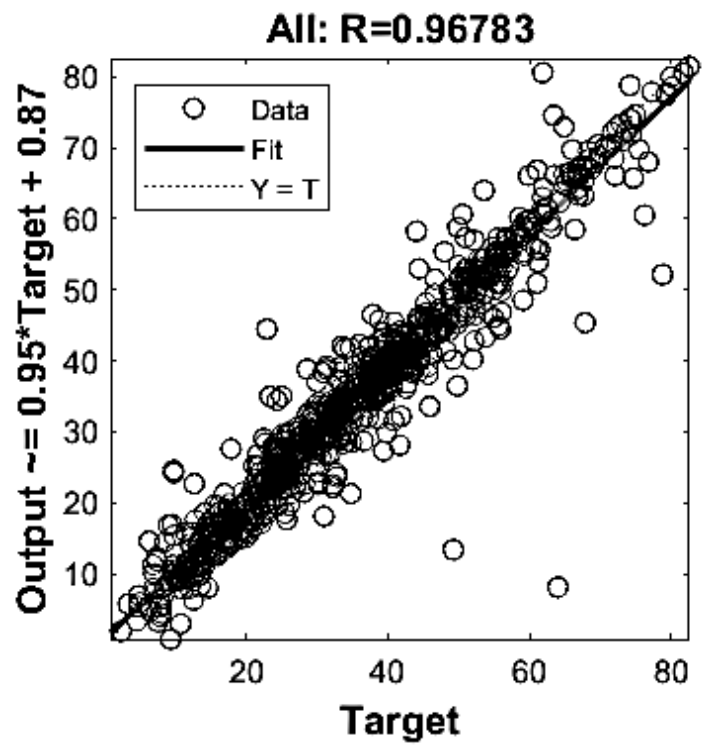

(d)

Figure 13. Regression for data training (a) Training regression; (b) Validation regression; (c) Test data regression; (d) Combined regression of training, validation and test data.

\subsection{Hidden Layers with (50 10) Number of Neurons}

Two hidden layers with number of neurons (50 10) were added to improve the performance of the ANN model. After training the ANN model, the performance of the second model with the implementation of Levenberg-Marquardt algorithm has increased as shown in Figure 14. The line fits the test data with a slope of 0.942 as shown in Figure 15 has increased than the previous model with 1 hidden layer and (50) number of neurons. The performance of validation data for this model, which is 2 hidden layers, (50 10) number of neurons in hidden layers is 28.33 . 


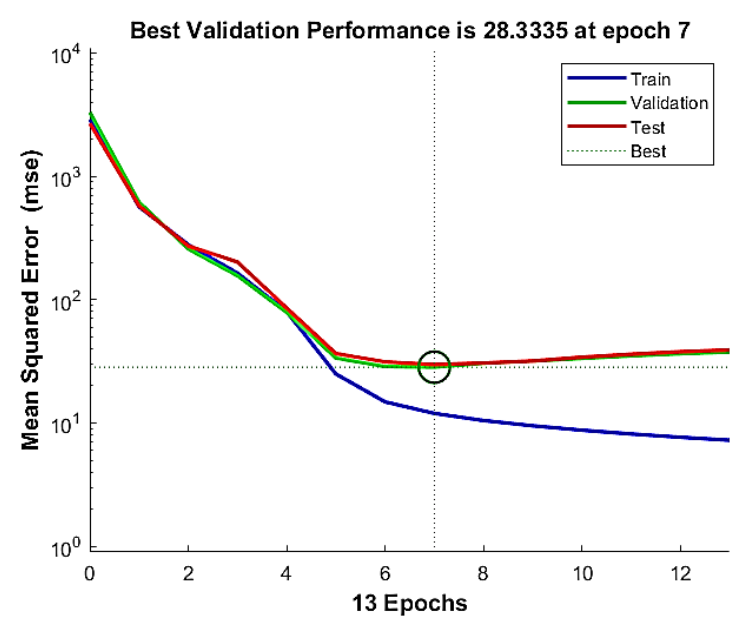

Figure 14. Two hidden layers neural network training performance.

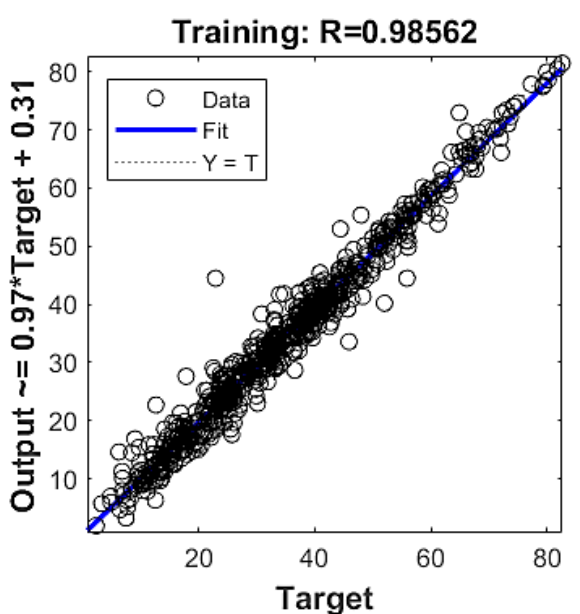

(a)

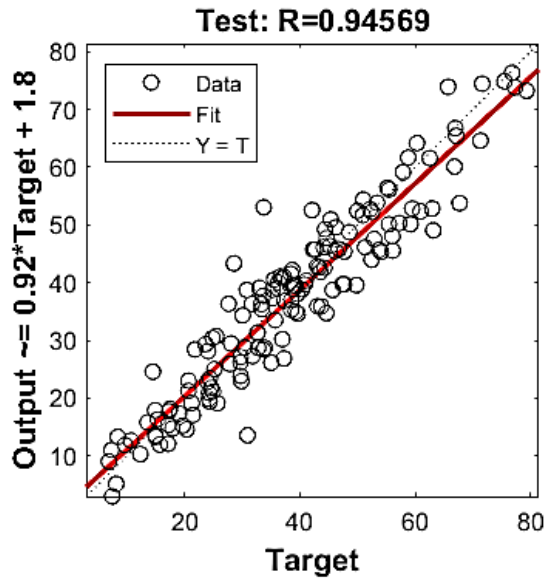

(c)

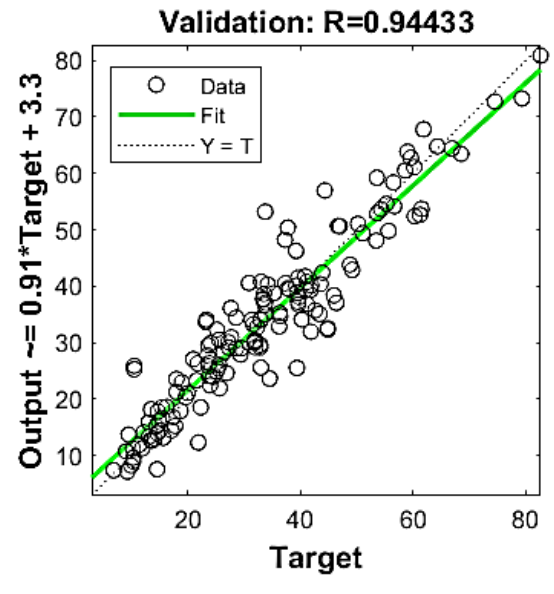

(b)

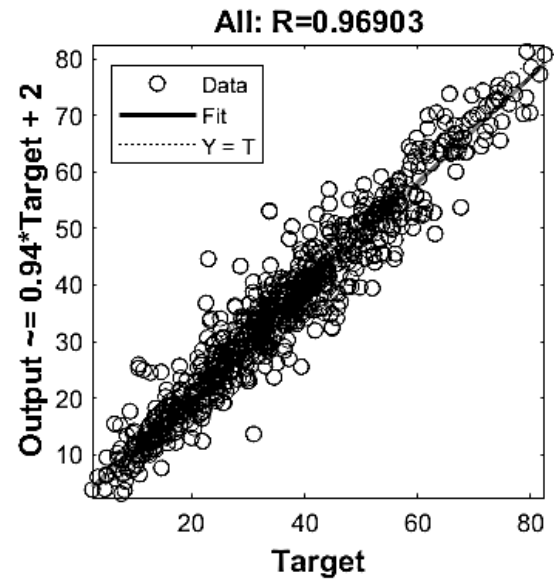

(d)

Figure 15. Two hidden layers ((50 10) number of neurons in hidden layers) neural network training regression (a) Training regression; (b) Validation regression; (c) Test data regression; (d) Combined regression of training, validation and test data. 


\subsection{Hidden Layers with (60 3) Number of Neurons}

Several modifications were made in order to develop a model with better accuracy where (60 3) neurons have been. Then, the Logsig and tansig are used as activation functions of hidden layers.

The third model (2 hidden layers, $(603)$ number of neurons in hidden layers with modified Activation function) has the Mean Square Error of 22.17 at epoch 16 as shown in Figure 16. Figure 17 shows the neural network training regression where the line fits the test data with a slope of 0.943 .

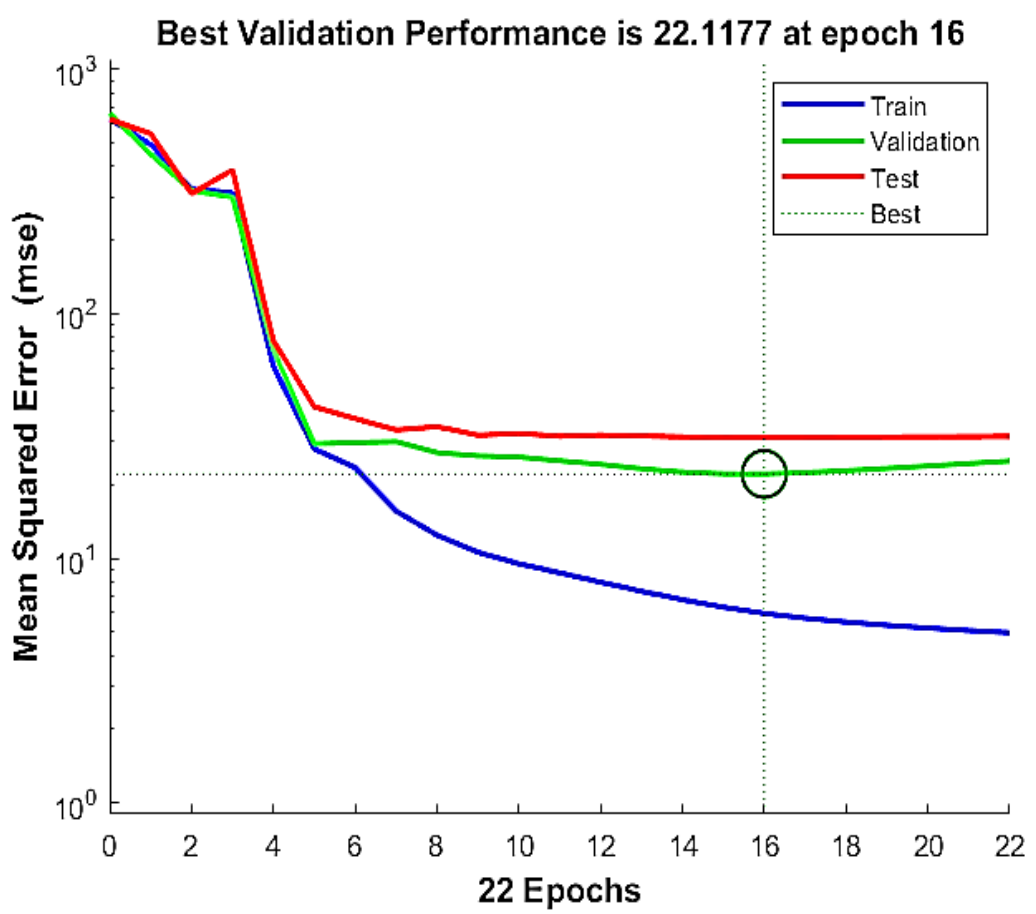

Figure 16. Neural network training performance (2 hidden layers with activation function).

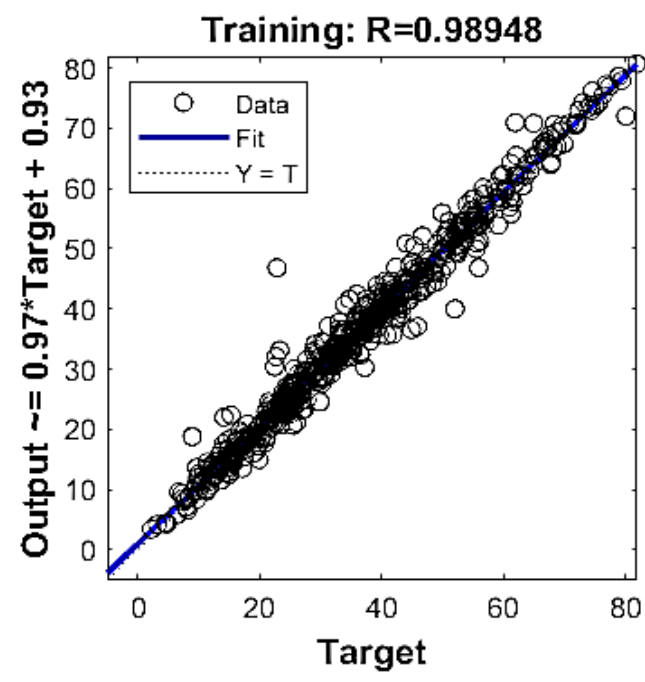

(a)

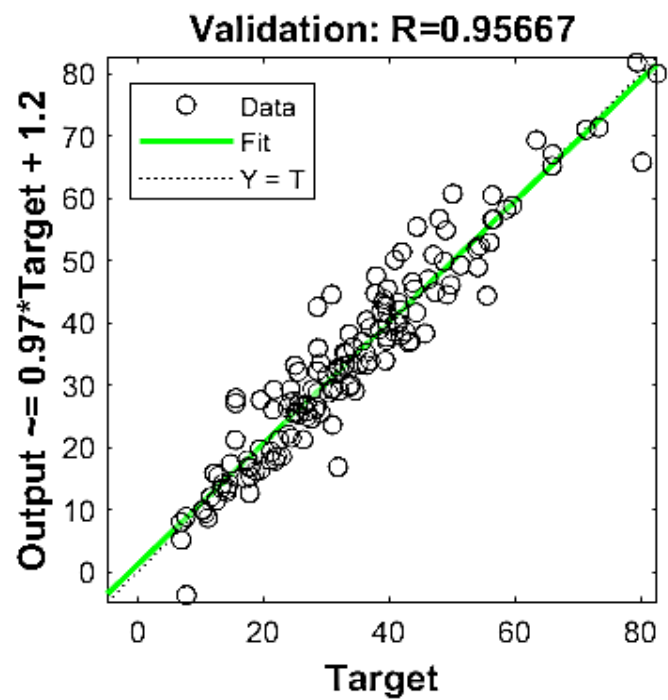

(b)

Figure 17. Cont. 


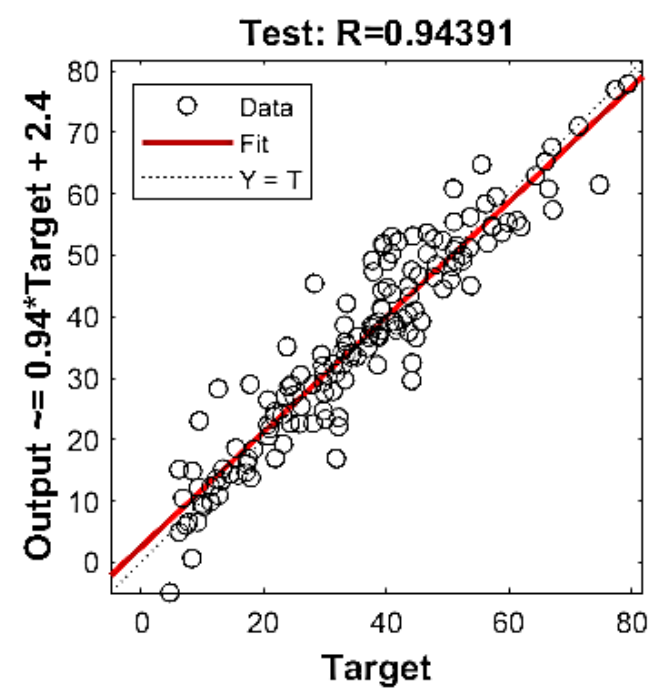

(c)

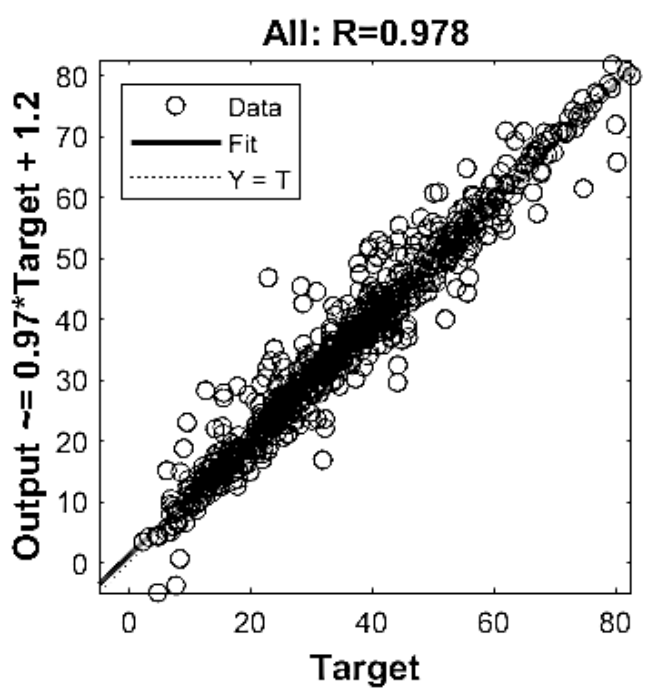

(d)

Figure 17. Two hidden layers ((603) number of neurons in hidden layers with activation function) neural network training regression (a) Training regression; (b) Validation regression; (c) Test data regression; (d) Combined regression of training, validation and test data.

\section{Discussions}

\subsection{Model Comparisons}

Table 6 compares the MSE and $\mathrm{R}^{2}$ obtained from three different models. It is found that, at first, the first model with 1 hidden layer and (50) number of neurons in hidden layer has the MSE of 34.81 and the line fits the test data with the slope of 0.924 which indicates the model is fit and reasonable. However, there is still room for improvement. In order to obtain a prediction model with high accuracy results and less error, some features and parameter of the ANN model need to be changed and configured. Hence, the available options are to increase the hidden layers and the number of neurons in hidden layers.

Table 6. Comparison of the models.

\begin{tabular}{ccccrr}
\hline Model & Hidden Layer & Number of Neurons in Hidden Layer & Transfer Function & MSE (Performance) & $\mathbf{R}^{\mathbf{2}}$ \\
\hline 1 & 1 & 50 & Sigmoid & 34.81 & 0.924 \\
2 & 2 & $(5010)$ & Sigmoid & 28.33 & 0.946 \\
3 & 2 & $(603)$ & Logsig and Tansig & 22.11 & 0.943 \\
\hline
\end{tabular}

Thus, with the help of Advance-Script in MATLAB, the second model has 2 hidden layers with $(5010)$ number of neurons in hidden layers. This time, the MSE of the second model has decreased from 34.81 (model 1) to 28.33 (model 2). The line fits the test data with a slope of 0.942 for model 2. Nevertheless, when a further modification of the number of hidden layers and number of neurons in hidden layers was made for model 3 where 2 hidden layers with Activation function (Logsig and Tansig), (60 3) number of neurons in hidden layers, the MSE for model 3 is 22.11, which is the lowest compared to model 1 and model 2. Meanwhile, the test line fits the test data with the slope of 0.943 , which is only a small change compared to model 2 , but model 3 has the highest correlation compared to model 1 and model 2.

After changing the number of neurons in hidden layers, activation function, and the number of hidden layers, the reasonable results that could predict the concrete compressive strength are achieved. It is known that a prediction model with large MSE performance value means the data values are dispersed widely around its central moment (mean), while a smaller MSE means the data values are concentrated or dispersed closely towards its central moment (mean). In other words, smaller MSE reflects on the distribution of data 
values and it is centralised, not entirely skewed. In other words, smaller MSE means the prediction has smaller errors, where the errors measured by the dispersion of data value from its mean. However, very small MSE performance value means the data is being overfit. In developing prediction models, it is important to ensure the data is not overfit and underfit. Hence, low MSE has smaller error which results in better prediction results.

The accuracy of the current model is compared with the previous studies published in the last decade together with the sample size, methods used and input and out variables as shown in Table 7. Previous studies mostly collected the recycled aggregates from the construction site and various sources while this study specifically provides the use of blast furnace slag. It is found that the accuracy of the current model seems to provide an accurate and precise results in comparison to the previous studies while the number of sample sizes of the current model is much larger than those in the past. This has proven that the current model is sufficient for predicting the recycled concrete strength by introducing the input variables into the model.

Table 7. Summary of the previous works on prediction model of recycled concrete.

\begin{tabular}{|c|c|c|c|c|c|}
\hline Reference & Sample Size & Method & $\mathbf{R}^{2}$ & Day & Remark \\
\hline [31] & 139 & ANN & 0.82 & - & $\begin{array}{l}\text { Type of recycled aggregate: Various sources } \\
\text { Input: w/c ratio, water absorption, fine aggregate, } \\
\text { recycled coarse aggregate, natural coarse } \\
\text { aggregate, water-total material ratio } \\
\text { Output: Compressive strength }\end{array}$ \\
\hline [32] & 40 & ANNS & 0.99 & 28 & $\begin{array}{l}\text { Type of recycled aggregate: Not specify (recycled } \\
\text { aggregate collected from the different sources of } \\
\text { construction and demolition waste) } \\
\text { Input: Water, cement, fine aggregate, coarse } \\
\text { aggregate and recycled aggregate } \\
\text { Output: Compressive strength and tensile } \\
\text { strength }\end{array}$ \\
\hline [33] & 74 & $\mathrm{CNN}$ & - & 7,28 & $\begin{array}{l}\text { Type of recycled aggregate: Not specify (recycled } \\
\text { aggregate collected from the pier of an abandoned } \\
\text { highway bridge) } \\
\text { Input: } \mathrm{w} / \mathrm{c} \text { ratio, recycled coarse aggregate } \\
\text { replacement ratio, recycled fine aggregate } \\
\text { replacement ratio and fly ash replacement ratio } \\
\text { Output: Compressive strength }\end{array}$ \\
\hline [37] & 17 & ANN, RSM & $0.99,0.98$ & $7,28,56$ & $\begin{array}{l}\text { Type of recycled aggregate: Not specify } \\
\text { Input: Cement content, ratio of recycled concrete } \\
\text { aggregates, slump } \\
\text { Output: Compressive strength }\end{array}$ \\
\hline [34] & 40 & $\begin{array}{l}\text { Genetic } \\
\text { Algorithm- } \\
\text { Back } \\
\text { Propagation } \\
\text { (GABP) }\end{array}$ & - & 28 & $\begin{array}{l}\text { Type of recycled aggregate: A combination of } \\
\text { recycled aggregate and vitrified micro bead } \\
\text { thermal insulation concrete } \\
\text { Input: Water binder ratio, cement, silica, } \\
\text { admixture, recycled aggregates, apparent density, } \\
\text { water absorption rate } \\
\text { Output: Compressive strength }\end{array}$ \\
\hline [35] & 5 & ANN & 0.99 & 7,28 & $\begin{array}{l}\text { Type of recycled aggregate: Lathe Waste Steel } \\
\text { Fibre (LWSF) } \\
\text { Input: Ordinary Portland cement, w/c ratio, age, } \\
\text { granite, river sand, recycled aggregate } \\
\text { Output: Compressive strength and tensile } \\
\text { strength }\end{array}$ \\
\hline
\end{tabular}


Table 7. Cont

\begin{tabular}{|c|c|c|c|c|c|}
\hline Reference & Sample Size & Method & $\mathbf{R}^{2}$ & Day & Remark \\
\hline This study & 1030 & ANN & 0.94 & $\begin{array}{c}1,3,7,14 \\
28,56,90 \\
180,279 \\
365\end{array}$ & $\begin{array}{l}\text { Type of recycled aggregate: Blast furnace slag as } \\
\text { recycled aggregate } \\
\text { Input: cement, water, coarse aggregate, fine } \\
\text { aggregate, superplasticizer, fly ash, blast furnace } \\
\text { slag, and age } \\
\text { Output: Compressive strength }\end{array}$ \\
\hline
\end{tabular}

\subsection{Predicted Recycled Aggregates Compressive Strength}

The predicted recycled aggregates compressive strength (highest and lowest compressive strength) is shown in Table 8.

Table 8. The highest and lowest predicted recycled aggregates compressive concrete strength.

\begin{tabular}{cccc}
\hline Parameter & Unit & \multicolumn{2}{c}{ Value } \\
\hline Cement & $\mathrm{kg} / \mathrm{m}^{3}$ & 0.15932 & 0.04789 \\
Blast Furnace Slag & $\mathrm{kg} / \mathrm{m}^{3}$ & 0.07723 & 0.07181 \\
Fly Ash & $\mathrm{kg} / \mathrm{m}^{3}$ & 0 & 0 \\
Water & $\mathrm{kg} / \mathrm{m}^{3}$ & 0.05962 & 0.08999 \\
Superplasticizer & $\mathrm{kg} / \mathrm{m}^{3}$ & 0.00898 & 0 \\
Coarse Aggregate & $\mathrm{kg} / \mathrm{m}^{3}$ & 0.38601 & 0.41488 \\
Fine Aggregate & $\mathrm{kg} / \mathrm{m}^{3}$ & 0.30883 & 0.37543 \\
Age & Day & 91 & 3 \\
Concrete Compressive Strength & $\mathrm{MPa}$ & 82.60 & 2.332 \\
\hline
\end{tabular}

Based on Table 8, from the 1030 data sets of concrete mixtures which comprise of 8 parameters such as cement, blast furnace slag, fly ash, water, superplasticizer, coarse aggregate, fine aggregate and age, the highest recycled aggregate concrete compressive strength predicted is $82.60 \mathrm{MPa}$. The lowest highest recycled aggregate concrete compressive strength predicted is $2.332 \mathrm{MPa}$, which shows there is a huge difference between the highest and the lowest predicted compressive concrete strength. The significant difference was ultimately influenced by the age of the recycled aggregate. The lowest concrete compressive strength is only 3 days old, while the highest concrete compressive strength is 91 days old.

Apart from that, the value of the superplasticizer of the lowest concrete compressive strength is zero compared to highest concrete compressive strength is $0.00898 \mathrm{~kg} / \mathrm{m}^{3}$. On the other hands, the cement composition for the lowest concrete compressive strength is only $0.004789 \mathrm{~kg} / \mathrm{m}^{3}$, lower than the highest predicted concrete compressive strength where the cement composition is $0.15932 \mathrm{~kg} / \mathrm{m}^{3}$.

However, the industrial concretes compressive strength mostly is tested at the age of 28 days old as the concrete achieve $90 \%$ of its designated strength at 28 days old [38].

The highest predicted concrete compressive strength for the recycled aggregates is $81.751 \mathrm{MPa}$ while the lowest is $8.5357 \mathrm{MPa}$ as shown in Table 9. Both recycled aggregates are 28 days old but there is a huge difference in terms of the concrete compressive strength. The cement composition for the highest concrete compressive strength recycled aggregates is $0.12712 \mathrm{~kg} / \mathrm{m}^{3}$, while the lowest concrete compressive strength has $0.07199 \mathrm{~kg} / \mathrm{m}^{3}$. The blast furnace slag for the highest value of concrete compressive strength is $0.00528 \mathrm{~kg} / \mathrm{m}^{3}$, the lowest value contains zero blast furnace slag. The $81.751 \mathrm{MPa}$ does not contain any fly ash, while the $8.5357 \mathrm{MPa}$ composed of $0.08884 \mathrm{~kg} / \mathrm{m}^{3}$ of fly ash. Moreover, the lowest value composed of $0.10023 \mathrm{~kg} / \mathrm{m}^{3}$ of water which is two times of the water composition of the $81.751 \mathrm{MPa}$. The other parameter does not show any significant difference in terms of parameter compositions. 
Table 9. The highest and lowest predicted recycled aggregates compressive concrete strength for 28 days old.

\begin{tabular}{cccc}
\hline \multirow{2}{*}{ Parameter } & Unit & Max & Min \\
\cline { 3 - 4 } & & 0.13723 & 0.07199 \\
\hline Cement & $\mathrm{kg} / \mathrm{m}^{3}$ & 0.00528 & 0 \\
\hline Blast Furnace Slag & $\mathrm{kg} / \mathrm{m}^{3}$ & 0 & 0.08884 \\
\hline Fly Ash & $\mathrm{kg} / \mathrm{m}^{3}$ & 0.05852 & 0.10023 \\
\hline Water & $\mathrm{kg} / \mathrm{m}^{3}$ & 0.00238 & 0.00501 \\
\hline Superplasticizer & $\mathrm{kg} / \mathrm{m}^{3}$ & 0.45603 & 0.40911 \\
\hline Coarse Aggregate & $\mathrm{kg} / \mathrm{m}^{3}$ & 0.30066 & 0.32483 \\
\hline Fine Aggregate & $\mathrm{kg} / \mathrm{m}^{3}$ & 28 & 28 \\
\hline Age & Day & 81.751 & 8.5357 \\
\hline
\end{tabular}

However, based on Tables 8 and 9, the age, cement and water compositions greatly affect the recycled aggregates concrete compressive strength. It is known that the water/cement ratio influenced the performance of the concrete in terms of strength and durability when it is completely cured. In concrete mix design, the ratio of the amount of water to the amount of cement used is called water to cement ratio. The water-cement ratio depends on the application of the concrete. In short, the greater the amount of water in a concrete mix, the more dilute the cement. Thus, the concrete compressive strength, tensile strength, flexural strength, porosity, shrinkage and colour are affected [39].

This is where the superplasticizer plays the role. The superplasticizer is an admixture where it acts as water-reducing retarders. The admixtures are mix with the concrete to achieve certain workability at a low water-cement ratio. This results in concrete with a specified strength at lower cement content where this method eventually saves the usage of the cement [40].

In Table 9, the highest value of concrete compressive strength, $81.751 \mathrm{MPa}$, contains $0.00238 \mathrm{~kg} / \mathrm{m}^{3}$ superplasticizer which is slightly lower than the $8.5357 \mathrm{MPa}$, where it contains $0.00501 \mathrm{~kg} / \mathrm{m}^{3}$. Even though the $81.751 \mathrm{MPa}$ has lower water composition compared to $8.5357 \mathrm{MPa}$, it contains $0.00528 \mathrm{~kg} / \mathrm{m}^{3}$ of blast furnace slag while for the $8.5357 \mathrm{MPa}$, it contains $0 \mathrm{~kg} / \mathrm{m}^{3}$ of blast furnace slag. Blast furnace slag used as a binder material to improve the properties of the concrete in terms of strength, watertightness, chemical resistance and ion permeation resistance [41].

Meanwhile, there is $0 \mathrm{~kg} / \mathrm{m}^{3}$ of fly ash for the $81.751 \mathrm{MPa}$ concrete compressive strength, while $8.5357 \mathrm{MPa}$ contain $0.8884 \mathrm{~kg} / \mathrm{m}^{3}$ of fly ash. Fly ash is fine ash produced at coal-fired power plants which can be used as prime material in many cement-based products to improve the workability, durability and the strength of the concrete [42]. Although the $81.751 \mathrm{MPa}$ does not contain any fly ash, it came out stronger than the 8.5357 MPa. This is due to the cement, water, superplasticizer and the blast furnace slag composition, which greatly affect the concrete compressive strength of the 28 days old recycled aggregates. The fly ash and blast furnace slag ratio also influenced the concrete compressive strength [43].

\section{Conclusions}

In this paper, three ANN prediction models have been developed to further study the impact of recycled aggregates on the strength of recycled concrete. ANN is utilised to train 8 elements of the recycled concrete to predict the concrete compressive strength of the recycled concrete from 1030 datasets. The three different models delivered different performances in terms of MSE and $\mathrm{R}^{2}$. Several modifications have been made to distinguish the three types of ANN prediction model, where model 1 (1 hidden layer with (50) number 
of neurons in hidden layers), model 2 (2 hidden layers with (50 10) number of neurons in hidden layers) and model 3 (2 hidden layers with activation function, (60 3) number of neurons in hidden layers). The increase of hidden layers and neurons in hidden layers and customisation of activation functions has been done in order to improve the performance of the ANN prediction model. The following key findings can be drawn as follows:

- Due to an extremely complex nonlinear relationship between mix ratio and the concrete strength, a machine learning prediction model is a reliable tool for the design mixture for the target concrete strength. The proposed models present the correlation coefficient of $0.92-0.94$ and mean square error of 22.11-34.81.

- The increase in the number of hidden layers and the number of neurons in hidden layers with customisation of activation function improves the performance of the ANN prediction model in terms of MSE.

- Model 3, with 2 hidden layers with activation function, (60 3) number of neurons in hidden layers, delivers the best performance with MSE value of 22.11, which indicates that this model has a smaller error and reliable prediction results. Thus, Model 3 is the most reliable model to predict the compressive strength of the recycled aggregate concrete.

Researchers can use this model to predict the concrete compressive strength with the consideration of blast finance slag as a recycled aggregate by inserting the concrete mix proportions including cement, water, fine aggregate, coarse aggregate, day, fly ash, superplasticizer and blast finance slag. It is noted that fly ash, superplasticizer and blast finance slag can be excluded in the current model as the datasets also contain the mix proportion without them.

Note that the number of datasets is limited in this study due to the lack of experimental data. Hence, more datasets need to be collected for future research. Once more datasets are collected, the more accurate prediction model with different inputs and outputs can be further investigated. As proven, that replacing the aggregates by recycled aggregates can greatly influence the concrete compressive strength so that it is also essential to try other types of recycled aggregates to find the best cost-effective and efficient aggregate for use in concrete in the future. It will be useful to enhance the properties and proportions relationship to the microstructure of concrete to understand its linkage and physical and chemical contributions from additives and admixtures that can be applied in the model. Thus, it is recommended to improve the prediction model in the future by including more input and output parameters for a better outcome and benefits to the engineers.

Author Contributions: Conceptualization, Y.W. and S.K.; methodology, Y.W.; software, Y.W.; validation, M.A.R.B.K.A., C.N., and S.K.; formal analysis, M.A.R.B.K.A.; investigation, M.A.R.B.K.A.; resources, M.A.R.B.K.A. and C.N.; writing-original draft preparation, M.A.R.B.K.A. and C.N.; writing-review and editing, C.N. and S.K.; visualization, M.A.R.B.K.A.; supervision, S.K.; project administration, S.K.; funding acquisition, S.K. All authors have read and agreed to the published version of the manuscript.

Funding: This research was funded by the European Commission, H2020-MSCA-RISE Project No. 691135 "RISEN: Rail Infrastructure Systems Engineering Network".

Acknowledgments: The authors are sincerely grateful to European Commission for the financial sponsorship of the H2020-MSCA-RISE Project No. 691135 “RISEN: Rail Infrastructure Systems Engineering Network," which enables a global research network that tackles the grand challenge of railway infrastructure resilience and advanced sensing in extreme environments (www.risen2rail. eu) [44]. This project has partially received funding from the Shift2Rail Joint Undertaking under the European Union's Horizon 2020 research and innovation programme under grant agreement No 730849 .

Conflicts of Interest: The authors declare no conflict of interest. 


\section{References}

1. Tam, V.W.Y.; Shen, L.Y.; Fung, I.W.H.; Wang, J.Y. Controlling Construction Waste by Implementing Governmental Ordinances in Hong Kong. Constr. Innov. 2007, 7, 149-166.

2. Cowan, H. A history of masonry and concrete domes in building construction. Build. Environ. 1977, 12, 1-24. [CrossRef]

3. Swe, T.M.; Jongvivatsakul, P.; Pansuk, W. Properties of Pervious Concrete Aiming for LEED Green Building Rating System Credits. Eng. J. 2016, 20, 61-72. [CrossRef]

4. You, R.; Goto, K.; Ngamkhanong, C.; Kaewunruen, S. Nonlinear finite element analysis for structural capacity of railway prestressed concrete sleepers with rail seat abrasion. Eng. Fail. Anal. 2019, 95, 47-65. [CrossRef]

5. Kaewunruen, S.; Ngamkhanong, C.; Lim, C.H. Damage and failure modes of railway prestressed concrete sleepers with holes/web openings subject to impact loading conditions. Eng. Struct. 2018, 176, 840-848. [CrossRef]

6. Sims, I.; Lay, J.; Ferrari, J. Concrete Aggregates. In Lea's Chemistry of Cement and Concrete (Fifth Edition); Hewlett, P.C., Liska, M., Eds.; Butterworth-Heinemann: Oxford, UK, 2019; pp. 699-778.

7. Huang, X.; Ge, J.; Kaewunruen, S.; Su, Q. The Self-Sealing Capacity of Environmentally Friendly, Highly Damped, FibreReinforced Concrete. Materials 2020, 13, 298. [CrossRef]

8. Daungwilailuk, T.; Cao, T.N.; Pansuk, W.; Pheinsusom, P. Evaluating Damaged Concrete Depth in Reinforced Concrete Structures under Different Fire Exposure Times by Means of NDT and DT Techniques. Eng. J. 2017, 21, 233-249. [CrossRef]

9. Jiradilok, P.; Wang, Y.; Nagai, K.; Matsumoto, K. Development of discrete meso-scale bond model for corrosion damage at steel-concrete interface based on tests with/without concrete damage. Constr. Build. Mater. 2020, 236, 117615. [CrossRef]

10. Daungwilailuk, T.; Kitagawa, T.; Bui, P.T.; Ogawa, Y.; Kawai, K. Penetration of Moisture, $\mathrm{CO}_{2}$, and $\mathrm{Cl}$ Ions in Concrete after Exposure to High Temperature. J. Adv. Concr. Technol. 2019, 17, 1-15. [CrossRef]

11. Mizoguchi, M.; Kitagawa, T.; Daungwilailuk, T.; Ogawa, Y.; Kawai, K. Investigation on Moisture Transfer in Mortar after Exposure to High Temperature. In Icscea 2019; Springer: Singapore, 2020; pp. 563-572. [CrossRef]

12. Carvalho, F.P. Mining industry and sustainable development: Time for change. Food Energy Secur. 2017, 6, 61-77. [CrossRef]

13. Crow, J.M. The Concrete Conundrum. Available online: https://www.chemistryworld.com (accessed on 4 December 2020).

14. Kaewunruen, S.; Meesit, R. Eco-friendly High-Strength Concrete Engineered by Micro Crumb Rubber from Recycled Tires and Plastics for Railway Components. Adv. Civ. Eng. Mater. 2020, 9, 210-226. [CrossRef]

15. Nguyen, H.Y.T.; Pansuk, W.; Sancharoen, P. The Effects of Electro-Chemical Chloride Extraction on the Migration of Ions and the Corrosion State of Embedded Steel in Reinforced Concrete. KSCE J. Civ. Eng. 2018, 22, 2942-2950. [CrossRef]

16. Ouchi, M.; Kameshima, K.; Attachaiyawuth, A. Improvement in Self-compacting Properties of Fresh Concrete by Eliminating Large Air Bubbles using an Antifoaming Agent. J. Adv. Concr. Technol. 2017, 15, 10-18. [CrossRef]

17. Arora, S. Recycled Aggregates: A Sustainable Solution of Construction and Demolished Waste. IOSR AETM'15 J. Mech. Civ. Eng. 2015, 2, 58-63.

18. Spaeth, V.; Tegguer, A.D. Improvement of recycled concrete aggregate properties by polymer treatments. Int. J. Sustain. Built Environ. 2013, 2, 143-152. [CrossRef]

19. Kaewunruen, S. Systemic Values of Enhanced Dynamic Damping in Concrete Sleepers-Comments on the Paper: Ahn S, Kwon S, Hwang Yt, Koh Hi, Kim Hs, Park J. Complex Structured Polymer Concrete Sleeper for Rolling Noise Reduction of High-Speed Train System, Composite Structures, 2019, 223: 110944. Compos. Struct. 2020, 234, 111711.

20. Malešev, M.; Radonjanin, V.; Marinković, S. Recycled Concrete as Aggregate for Structural Concrete Production. Sustainability 2010, 2, 1204-1225. [CrossRef]

21. Etxeberria, M.; Vázquez, E.; Marí, A.; Barra, M. Influence of amount of recycled coarse aggregates and production process on properties of recycled aggregate concrete. Cem. Concr. Res. 2007, 37, 735-742. [CrossRef]

22. Akbarnezhad, A.; Ong, K.C.G.; Tam, C.T.; Zhang, M.H. Effects of the Parent Concrete Properties and Crushing Procedure on the Properties of Coarse Recycled Concrete Aggregates. J. Mater. Civ. Eng. 2013, 25, 1795-1802. [CrossRef]

23. Wang, Y.; Jiradilok, P.; Nagai, K.; Asamoto, S. A mesoscale discrete model for mechanical performance of concrete damaged by coupled ASR and DEF. Eng. Fract. Mech. 2020, 232, 107055. [CrossRef]

24. Puthipad, N.; Ouchi, M.; Attachaiyawuth, A. Effects of fly ash, mixing procedure and type of air-entraining agent on coalescence of entrained air bubbles in mortar of self-compacting concrete at fresh state. Constr. Build. Mater. 2018, 180, 437-444. [CrossRef]

25. González-Taboada, I.; González-Fonteboa, B.; Martínez-Abella, F.; Carro-López, D. Study of recycled concrete aggregate quality and its relationship with recycled concrete compressive strength using database analysis. Mater. Constr. 2016, 66, e089. [CrossRef]

26. Attachaiyawuth, A.; Rath, S.; Tanaka, K.; Ouchi, M. Improvement of Self-Compactability of Air-Enhanced Self-Compacting Concrete with Fine Entrained Air. J. Adv. Concr. Technol. 2016, 14, 55-69. [CrossRef]

27. Eddy, L.; Jiradilok, P.; Matsumoto, K.; Nagai, K. Analytical investigation of the role of reinforcement in perpendicular beams of beam-column knee joints by 3D meso-scale model. Eng. Struct. 2020, 210, 110347. [CrossRef]

28. Kim, Y.-Y.; Lee, K.-M.; Bang, J.-W.; Kwon, S.-J. Effect of W/C Ratio on Durability and Porosity in Cement Mortar with Constant Cement Amount. Adv. Mater. Sci. Eng. 2014, 2014, 1-11. [CrossRef]

29. Cantero, B.; Del Bosque, I.S.; Matías, A.; Medina, C. Statistically significant effects of mixed recycled aggregate on the physicalmechanical properties of structural concretes. Constr. Build. Mater. 2018, 185, 93-101. [CrossRef]

30. Park, Y.S.; Lek, S. Artificial Neural Networks: Multilayer Perceptron for Ecological Modeling. In Developments in Environmental Modelling; Jørgensen, S.E., Ed.; Elsevier: Amsterdam, The Netherlands, 2016; pp. 123-140. 
31. Naderpour, H.; Rafiean, A.H.; Fakharian, P. Compressive strength prediction of environmentally friendly concrete using artificial neural networks. J. Build. Eng. 2018, 16, 213-219. [CrossRef]

32. Paul, S.C.; Panda, B.; Garg, A. A novel approach in modelling of concrete made with recycled aggregates. Measurement 2018, 115, 64-72. [CrossRef]

33. Deng, F.; He, Y.; Zhou, S.; Yu, Y.; Cheng, H.; Wu, X. Compressive strength prediction of recycled concrete based on deep learning Constr. Build. Mater. 2018, 175, 562-569. [CrossRef]

34. Tu, J.; Liu, Y.; Zhou, M.; Li, R. Prediction and analysis of compressive strength of recycled aggregate thermal insulation concrete based on GA-BP optimization network. J. Eng. Des. Technol. 2020. [CrossRef]

35. Alabi, S.A. Predictive Models for Evaluation of Compressive and Split Tensile Strengths of Recycled Aggregate Concrete Containing Lathe Waste Steel Fiber. Jordan J. Civ. Eng. 2020, 14, 598-605.

36. Kandiri, A.; Sartipi, F.; Kioumarsi, M. Predicting Compressive Strength of Concrete Containing Recycled Aggregate Using Modified ANN with Different Optimization Algorithms. Appl. Sci. 2021, 11, 485. [CrossRef]

37. Hammoudi, A.; Moussaceb, K.; Belebchouche, C.; Dahmoune, F. Comparison of artificial neural network (ANN) and response surface methodology (RSM) prediction in compressive strength of recycled concrete aggregates. Constr. Build. Mater. 2019, 209, 425-436. [CrossRef]

38. Frías-Rojas, M.; Sánchez-de-Rojas-Gómez, M.I.; Medina-Martínez, C.; Villar-Cociña, E. 6-New Trends for Nonconventional Cement-Based Materials: Industrial and Agricultural Waste. In Sustainable and Nonconventional Construction Materials Using Inorganic Bonded Fiber Composites; Savastano, H., Jr., Fiorelli, J., dos Santos, S.F., Eds.; Woodhead Publishing: Cambridge, UK, 2017; pp. 165-183.

39. Aitcin, P.-C. The Influence of the Water/Cement Ratio on the Sustainability of Concrete. In Lea's Chemistry of Cement and Concret, 4th ed.; Hewlett, P.C., Liska, M., Eds.; Butterworth-Heinemann: Oxford, UK, 2019; pp. 807-826.

40. Mardani-Aghabaglou, A.; Tuyan, M.; Yilmaz, G.; Arıöz, Ö.; Ramyar, K. Effect of different types of superplasticizer on fresh, rheological and strength properties of self-consolidating concrete. Constr. Build. Mater. 2013, 47, 1020-1025. [CrossRef]

41. Jariyathitipong, P.; Hosotani, K.; Fujii, T.; Ayano, T. Strength and Durability of Concrete with Blast Furnace Slag. In Proceedings of the 3rd International Conference on Sustainable Construction Materials and Technologies, SCMT 2013, Kyoto, Japan, 18-21 August 2013.

42. Bijen, J. Benefits of slag and fly ash. Constr. Build. Mater. 1996, 10, 309-314. [CrossRef]

43. Humad, A.M.; Kothari, A.; Provis, J.L.; Cwirzen, A. The Effect of Blast Furnace Slag/Fly Ash Ratio on Setting, Strength, and Shrinkage of Alkali-Activated Pastes and Concretes. Front. Mater. 2019, 6. [CrossRef]

44. Kaewunruen, S.; Sussman, J.M.; Matsumoto, A. Grand challenges in transportation and transit systems. Front. Built Environ. 2016, 2. [CrossRef] 